1 - ORIGINAL ARTICLE

WOUND HEALING

\title{
Repair of surgical wounds in rats using a $10 \%$ unripe Musa sapientum peel gel ${ }^{1}$
}

\author{
Dênia Amélia Novato Castelli Von Atzingen ${ }^{\mathrm{I}}$, Adriana Rodrigues dos Anjos Mendonça ${ }^{\mathrm{II}}$, Marcos Mesquita Filho ${ }^{\mathrm{III}}$, Vinícius Alves \\ Alvarenga $^{I v}$, Vinícius Almeida Assisv, Afonso Esteves Penazzov, Julio Henrique Muzettiv, Thaisa Sousa Rezendev
}

DOI: http://dx.doi.org/10.1590/S0102-865020150090000001

IPhD, Associate Professor, School of Medical Sciences, Universidade do Vale do Sapucaí (UNIVÁS), Pouso Alegre-MG, Brazil. Conception, design, intellectual and scientific content of the study; surgical procedures; acquisition of data; manuscript writing; critical revision.

${ }^{I I} \mathrm{PhD}$, Full Professor, School of Medical Sciences, UNIVÁS, Pouso Alegre-MG, Brazil. Conception and design of the study, surgical procedures, acquisition and interpretation of data, critical revision.

IIIPhD, Full Professor, School of Medical Sciences, UNIVÁS, Pouso Alegre-MG, Brazil. Design of the study, statistical analysis, interpretation of data, critical revision.

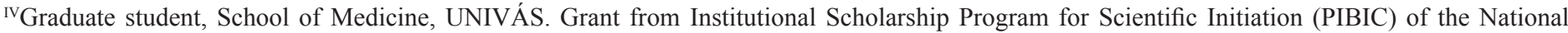
Council of Scientific and Technological Development (CNPq) Ministry of Science, Technology and Innovation, Brazil. Surgical procedures, acquisition and interpretation of data, manuscript preparation.

${ }^{v}$ Graduate student, School of Medicine, UNIVÁS. Grant from Institutional Scholarship Program for Scientific Initiation (PIBIC) of the National Council of Scientific and Technological Development (CNPq) Ministry of Science, Technology and Innovation, Brazil. Surgical procedures, acquisition of data, manuscript preparation.

\section{ABSTRACT}

PURPOSE: To investigate the efficacy of a 10\% gel of unripe banana (Musa sapientum) peel in treating surgical wounds in rats.

METHODS: A longitudinal, prospective, randomized triple-blind study was conducted with 60 Wistar rats (Rattus norvegicus albinus) weighing approximately $400 \mathrm{~g}$. The animals were randomly divided into: control group (treated with gel containing no active ingredient) and study group (treated with $10 \%$ gel of unripe banana peel). The gel was applied every three days to a $4 \mathrm{x} 4-\mathrm{cm}$ surgical wound created on the back of each animal (day 0) in both groups. Tissue samples were collected for histological analysis on days 14, 21 and 28.

RESULTS: On day 14 , more extensive vascular proliferation $(\mathrm{p}=0.023)$, presence of mononuclear cells $(\mathrm{p}=0.000)$, fibroblast proliferation $(p=0.012)$, re-epithelialization $(p=0.000)$, and decreased presence of polymorphonuclear cells $(p=0.010)$ were observed in the study group than in controls. No significant between-group difference in the presence of polymorphonuclear cells was found on day 21 . Fibroblast proliferation was significantly greater $(\mathrm{p}=0.006)$ in the study group than in the control group on day 28 .

CONCLUSION: The 10\% gel of unripe banana peel showed anti-inflammatory activity and stimulated wound healing in rat skin when compared with a gel containing no active ingredient.

Key words: Wound Healing. Skin. Musa sapientum. Models, Animal. Rats. 


\section{Introduction}

The prevalence of chronic wounds in the general population is relatively high. This condition is associated with several diseases and imposes a major social and economic burden on patients and healthcare systems. Thus, the search for alternative therapies for the management of chronic wounds is of fundamental importance ${ }^{1,2}$. There are many treatment options for chronic wounds on the market, but it has been difficult to properly determine the cost-benefit relationship and best treatment option for each type of ulceration $^{3}$. Despite the predominance of synthetic substances in the therapeutic arsenal, including anti-inflammatory drugs, recent years have witnessed a renewed interest in therapeutic practices considered by many health professionals as popular or unscientific. Many phytotherapeutics, including extracts of Aloe vera, passion fruit (Passiflora edulis), aroeira (Schinus terebinthifolius), and unripe banana (M. sapientum) have been tested and used in the treatment of skin lesions ${ }^{4,5}$.

Banana (Musa sapientum) is a common tropical fruit; it was brought to Brazil by the Portuguese. Unripe banana extract promotes increased incorporation of thymidine into cellular DNA, which enhances cell proliferation ${ }^{2}$. Unripe banana peel contains leucocyanidin, a flavonoid that induces cell proliferation, accelerating the healing of skin wounds ${ }^{6}$. The pulp and peel of unripe banana have been used in the treatment of cracked nipples and peptic ulcers in humans ${ }^{2}$. The active agent in unripe bananas is water soluble and becomes inactive in ripe bananas? Further studies are being conducted by this research team. If its therapeutic efficacy is confirmed, unripe banana would be a new and inexpensive treatment option for skin wounds, accessible to the general population.

The purpose of this study was to investigate the efficacy of a $10 \%$ gel of unripe banana peel in treating skin wounds in rats.

\section{Methods}

This experimental, longitudinal, prospective, analytic, randomized, triple-blind study was approved by the Animal Care and Use Committee at Universidade do Vale do Sapucaí (UNIVÁS), approval number 161/12.

The animals were obtained from the Laboratory Animal Facility of UNIVÁS. The use of laboratory animals followed the principles of the Brazilian College on Animal Experimentation (COBEA), the Federal Law number 11.794 (08/10/2008) and the decree $6.689(15 / 07 / 2009)$. The study is classified as United States Department of Agriculture (USDA) Category $\mathrm{C}$ for laboratory animal usage.
The sample consisted of 60 adult male Wistar rats (Rattus norvegicus albinus) aged about 120 days and weighing approximately 400 grams. All animals were marked for identification. The rats were randomly divided into two groups (study and control groups) of 30 animals each, and each group was subdivided into three subgroups of 10 animals each according to the time of euthanasia, using the BioEstat 5.0 software. The allocation sequence was concealed in sequentially numbered, opaque, sealed envelopes. In this triple-blind study, the investigator, pathologist and statistician were blind to group assignment.

Animals in the control group were treated with natrosol gel (hydroxyethyl cellulose) without the active ingredient and those in the study group were treated with natrosol gel containing $10 \%$ of extract from unripe banana peel.

A 4 x 4-cm wound was created on the back of each animal. The wound was cleaned every 3 days from the immediate postoperative period to the day of euthanasia. The size of the wound was then measured with a caliper (Figure 1). The wound area was calculated by multiplying the longest length by the widest width of the wound. Next, the wound was treated with $10 \%$ gel or natrosol gel (control) and covered with gauze and adhesive tape.

Samples for histological analysis were collected on postoperative days 14, 21 and 28, with the animals anesthetized and alive. After sampling, the rats were euthanized by anesthetic overdose.

\section{Gel preparation}

The gel used in the study was prepared from unripe banana (M. sapientum) peels. Ripeness was determined according to the scale devised by Loeseck ${ }^{8}$, which relates ripeness to the color of the peel. Only completely unripe fruits were selected to ensure homogeneity.

First, the fruits were washed with running water and rubbed with a luffa sponge. After the first wash, the fruits were allowed to dry at room temperature for 20 minutes. The unripe bananas were then washed with $500 \mathrm{ml}$ of distilled water, dried with paper towel, and allowed to dry for another 20 minutes at room temperature. Next, the fruits were peeled and the pulp was discarded; only the peels were used. The peels were diced into cubes of approximately $1 \mathrm{~mm}^{3}$, transferred to a ceramic mortar, and manually ground with a pestle for 60 minutes until complete homogenization. The peel of one unripe banana yields about $50 \mathrm{~g}$ of ground peel. The ground peel was placed in a watch glass and weighed on a precision balance 
model Gehaka BG2000. Following, 100g of gel (10\% gel) was prepared by mixing $10 \mathrm{~g}$ of ground peel with $90 \mathrm{~g}$ of natrosol gel for five minutes to ensure homogenization. The prepared formulation was placed in a previously sterilized, white 120 -g plastic container having a false bottom, stored at refrigeration temperature, and used within 30 days.

\section{Surgical procedure}

Before the surgical procedure, the animals were anesthetized with a mixture of ketamine hydrochloride $(50 \mathrm{mg}$ ) and $2 \%$ xylazine hydrochloride $(20 \mathrm{mg}$ ) at $2 \mathrm{mg} / \mathrm{kg}$ body weight. The hair of a $6 \times 6-\mathrm{cm}$ area $\left(36 \mathrm{~cm}^{2}\right)$ in the dorsal region of the animals was manually removed in the cephalo-caudal direction. The incision lines were marked on the skin of the interscapular region between the anterior limbs with a thin felt tipped pen. The skin was cleaned with $0.9 \%$ saline and a 4 x 4 -cm surgical wound was created on the back of each animal (day 0). The incision was deepened to the dorsal muscular fascia and the dorsal skin was resected together with the panniculus carnosus (Figure 1).

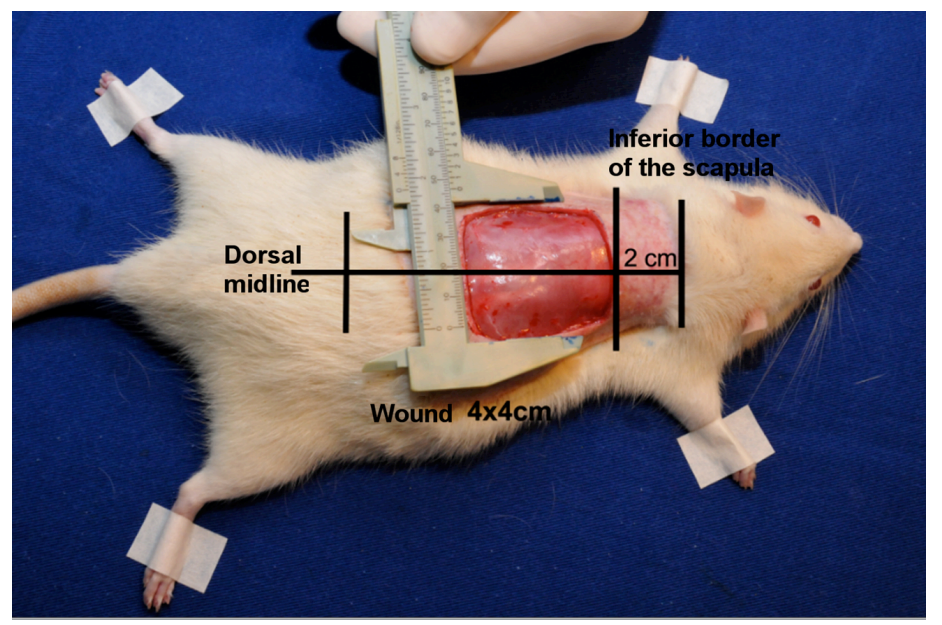

FIGURE 1 - Surgical wound.

All animals received sodium dipyrone at $1 \mathrm{mg} / \mathrm{kg}$ body weight three-times daily for postoperative analgesia during the study period.

\section{Treatment of surgical wounds}

All animals in both groups were treated every 3 days from the immediate postoperative period to the day of euthanasia. Before the treatment, the rats were anesthetized and the wounds were cleaned with $0.9 \%$ saline. Then, natrosol gel (control group) or 10\% unripe banana peel gel (study group) was applied to the surgical wound using a disposable wooden spatula, which was discarded after each application. The same amount of gel $(0.1 \mathrm{~g})$ was used in each application. The wound was covered with Transpore medical tape and a secondary dressing of microporous adhesive tape.

\section{Histological analysis}

Samples for histological analysis were collected on postoperative days 14, 21 and 28 with the animals anesthetized and alive. The tissue from the wound site was removed together with a $1 \mathrm{~cm}$ wide margin of normal skin, fixed in $10 \%$ buffered formalin, $\mathrm{pH} 7.5$, and sent to the pathology laboratory. Paraffinembedded specimens were cut into $3-\mu \mathrm{m}$ sections, mounted onto slides, and stained with hematoxylin and eosin (HE). The slides were photographed with a camera (model Canon PowerShot SX 100 IS) coupled to an optical microscope.

Histomorphological analysis was performed on micrographs to determine fibroblast proliferation, vascular proliferation and re-epithelialization, and quantify mononuclear and polymorphonuclear cells and collagen fiber content. Ten high-magnification fields of view $(x 40)$ were analyzed. The occurrence of cells was graded as slight $(<10$ mononuclear or polymorphonuclear cells), moderate (10 to 50 cells), or marked (>50 cells). All histological examinations were performed by the same pathologist, who was blinded to group allocation. Results were recorded for subsequent analysis.

\section{Statistical analysis}

Wound contraction rates at different time points (days 14, 21 and 28) were compared between and within groups using the chi-square test and Fisher's exact test.

Comparisons of the characteristics of the animals (e.g., age and body weight) between groups were made before and after the study intervention using Student's t- test.

Statistical analysis was carried out using the Statistical Package for the Social Sciences (SPSS) version 13.0. All statistical tests were performed at a significance level $\alpha$ of $0.05(\mathrm{p}<0.05)$.

\section{Results}

No significant differences in age and body weight of the animals were found between the study and control groups before and after the study intervention. 


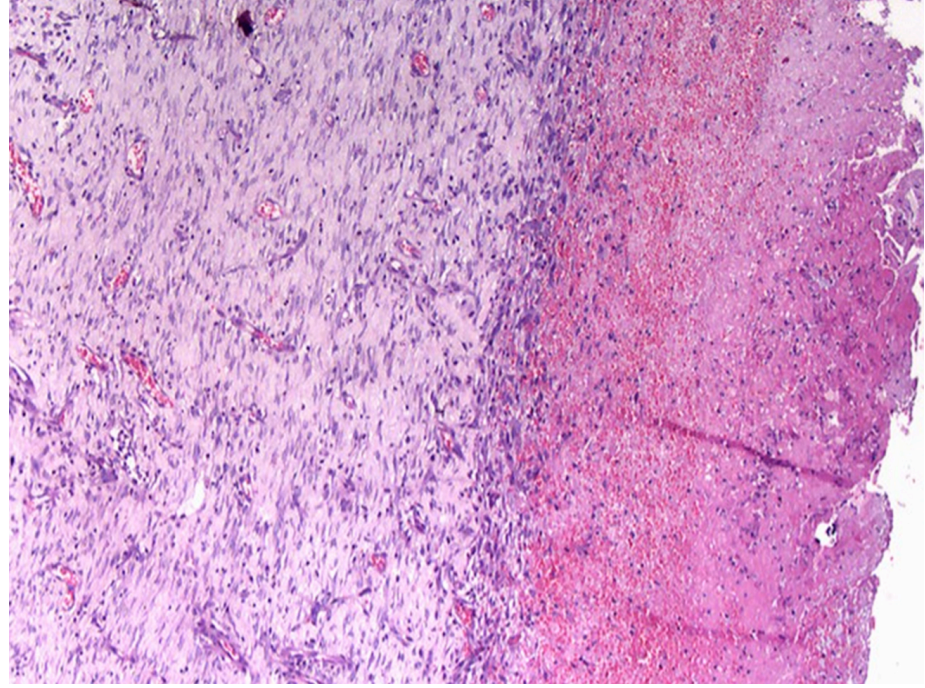

FIGURE 2 - Marked vascular and fibroblast proliferation.

\section{Histological analysis}

On day 14, wound healing was more advanced in the study group, which showed more extensive vascular proliferation $(p=0.023)$, presence of mononuclear cells $(p=0.000)$, fibroblast proliferation $(\mathrm{p}=0.012)$, and re-epithelialization $(\mathrm{p}=0.000)$ compared with the control group (Figure 2). There was also a smaller amount of polymorphonuclear cells in the study group than in the control group $(\mathrm{p}=0.010)$, suggesting a reduced inflammatory response to injury (Table 1).
Wound healing was still more advanced in the study group on day 21, which had more extensive vascular proliferation $(\mathrm{p}=0.008)$, presence of mononuclear cells $(\mathrm{p}=0.000)$, fibroblast proliferation $(\mathrm{p}=0.005)$, and re-epithelialization $(\mathrm{p}=0.000)$ than the control group. However, no significant difference in the presence of polymorphonuclear cells $(p=0.75)$ between groups was observed at this time point (Table 1).

Fibroblast proliferation was significantly greater $(\mathrm{p}=$ 0.006) in the study group compared with the control group on day 28 (Figure 3), with no significant between group-differences in other variables (Table 1).

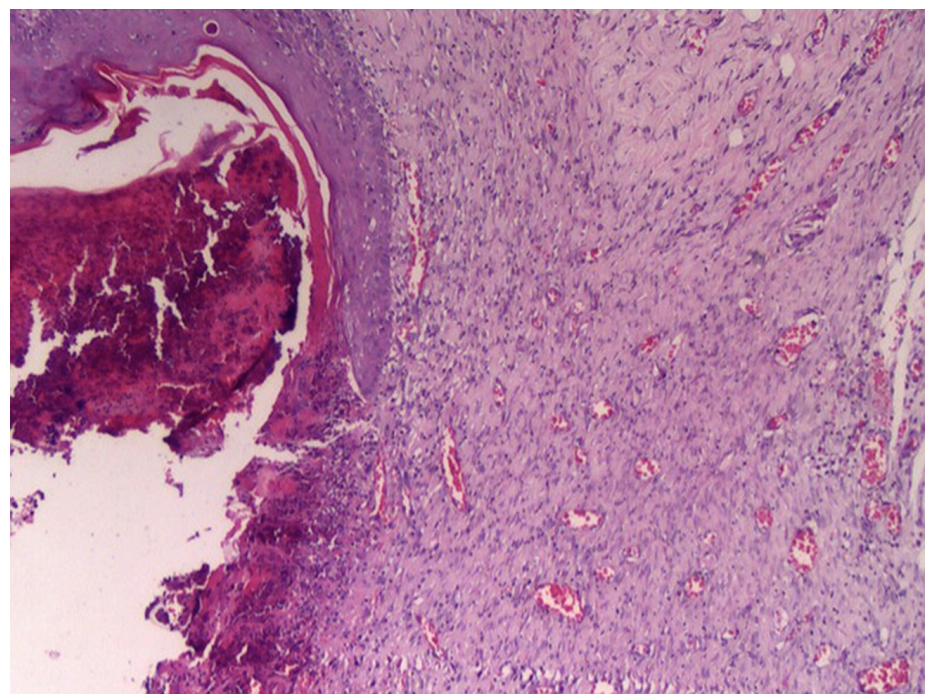

FIGURE 3 - Marked vascular and fibroblast proliferation and moderate re-epithelialization. 
TABLE 1 - Histological results for both groups at the three time points.

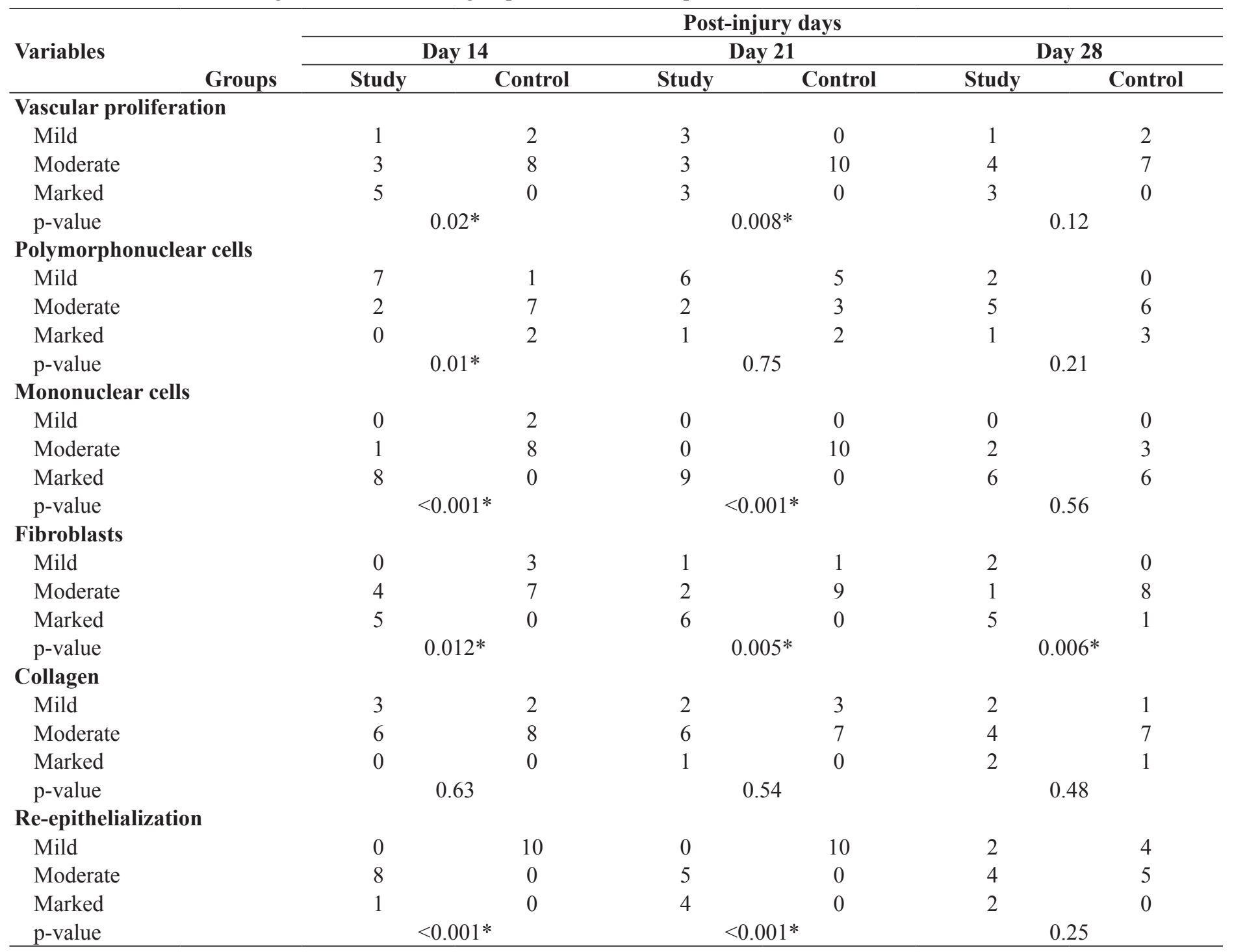

*Statistical significance $(\mathrm{p}<0.05)$

\section{Discussion}

Brazilian socioeconomic status and biodiversity has prompted an intensive search for reliable and less expensive solutions to the most prevalent conditions. Skin wounds affect a large part of the population, especially the poor. Brazil has the largest biodiversity of the world. The use of this vast biodiversity associated with a low-cost production of medications may provide a solution for several public health problems in Brazil.

Plantain banana (M. sapientum var. paradisiaca) has been intensively studied in the past 30 years. Unripe banana has been found to be helpful in treating peptic ulcers ${ }^{7,8}$. Further research has been conducted based on its healing properties, especially studies on skin wounds, which are very common and require prolonged treatments that often burden the health care system and the patient.

No study was found in the literature identifying the components of $M$. sapientum var. paradisiaca specifically responsible for its healing properties. However, studies on the properties of the banana, showed that especially its pulp is rich in flavonoids such as leucocyanidin, which has anti-inflammatory and anticancer activities ${ }^{9,10}$.

\section{Histological analysis}

In the beginning of the inflammation phase of wound healing there is an increase in vascular permeability, extravasation 
of plasma, erythrocytes, platelets, and leukocytes, especially neutrophils, monocytes and macrophages ${ }^{12,13}$. The inflammatory response is an important step of wound healing that prepares the environment of the wound for the repairing process. In this study, the use of the $10 \%$ gel of unripe banana peel significantly increased the inflammatory response on postoperative day 14 in the study group compared to the control group. This increase in inflammatory response may contribute to a reduction in healing time. However, this stage should not be very intense, because an excessive inflammatory response can cause delay in wound healing and favor an imbalance between synthesis and degradation of collagen, promoting matrix degradation ${ }^{11}$. Lack of neutrophils in the blood seems not to affect tissue repair in the absence of infection ${ }^{12-14}$.

Re-epithelialization begins few hours after injury with the migration of epithelial cells from the margins and epidermal appendages located in the center of the wound. Fibroplasia and vascular proliferation are of fundamental importance in wound healing because they are involved in the formation of granulation tissue, which gradually fills the wound cavity four days after injury. Although total re-epithelialization was not achieved with the use of unripe banana peel gel, re-epithelialization was significantly greater in the study group compared with that of the control group on postoperative days 14 and 21, showing that the gel stimulated wound contraction. Wound chronicity began on day 28 , with a reduction in the inflammatory process and significant increase in fibroblast proliferation in the study group compared to that of the control group. Fibroblasts produce new extracellular matrix required for cell growth, while new blood vessels carry oxygen and nutrients required for cell metabolism ${ }^{15}$. After platelets leave the vascular bed, neutrophils and mononuclear cells also migrate toward the wound area in response to chemotactic agents 5 . Macrophages produce various growth factors, such as plateletderived growth factor (PDGF), transforming growth factor-beta (TGF- $\beta$ ), fibroblast growth factor (FGF), and vascular endothelial growth factor (VEGF), which are the main cytokines necessary to stimulate granulation tissue formation ${ }^{15}$.

In the present study, $10 \%$ unripe banana peel gel positively affected wound healing, which is in agreement with other studies in the literature. The gel concentration was chosen based on a previous study, in which the $10 \%$ gel resulted in epithelialization of wounds healed by secondary intention ${ }^{1}$. Samples for histological analysis were collected on postoperative days 14, 21 and 28. No sampling was performed before day 14 because a previous 7-day study on the effect of unripe banana peel gel on wound healing in rats $^{1}$ has shown no significant differences in the studied parameters between the study and control groups.
Therefore, in this study, a longer study period was evaluated, with sampling beginning on day 14

Although the present study was performed in acute wounds, the $10 \%$ gel may be used in chronic wounds. This may be inferred by comparing the evolution of the wounds at different time points (i.e., at 14, 21 and 28 days of treatment). Other study has evaluated the effect of unripe banana peel gel at a different time interval ${ }^{1}$, suggesting that our findings may also be relevant to the treatment of chronic wounds. Further studies are necessary to confirm the beneficial effects of this gel and extend our results.

\section{Conclusion}

The $10 \%$ gel of unripe banana peel showed antiinflammatory action and stimulated wound healing in rat skin when compared with a gel containing no active ingredient.

\section{References}

1. Atzingen DA, Gragnani A, Veiga DF, Abla LE, Mendonça AR, Paula CA, Juliano Y, Correa JC, Faria MR, Ferreira LM. Gel from unripe Musa sapientum peel to repair surgical wounds in rats. Acta Cir Bras. 2011 Oct;26(5):379-82. PMID: 21952661.

2. Novak FR, de Almeida JA, de Souza e Silva R. Banana peel: a possible source of infection in the treatment of nipple fissures. $\mathrm{J}$ Pediatr (Rio J). 2003 May-Jun;79(3):221-6. PMID: 14506531.

3. Hoppe IC, Granick MS. Debridement of chronic wounds: a qualitative systematic review of randomized controlled trials. Clin Plast Surg. 2012 Jul;39(3):221-8. doi: 10.1016/j.cps.2012.04.001.

4. Garros IC, Campos AC, Tâmbara EM, Tenório SB, Torres OJ, Agulham MA, Araújo AC, Santis-Isolan PM, Oliveira RM, Arruda EC. Extract from Passiflora edulis on the healing of open wounds in rats: morphometric and histological study. Acta Cir Bras. 2006;21 Suppl 3:55-65. PMID: 17293938.

5. Branco Neto ML, Ribas Filho JM, Malafaia O, Oliveira Filho MA, Czeczko NG, Aoki S, Cunha R, Fonseca VR, Teixeira HM, Aguiar LR. Evaluation of hydroalcoholic extract of Aroeira (Shinus Terebinthifolius Raddi) in the healing process of wound skin in rats. Acta Cir Bras. 2006;21 Suppl 2:17-22. PMID: 17117273.

6. Lewis DA, Fields WN, Shaw GP. A natural flavonoid present in unripe plantain banana pulp (Musa sapientum L. var. paradisiaca) protects the gastric mucosa from aspirin-induced erosions. J Ethnopharmacol. 1999 Jun;65(3):283-8. PMID: 10404428.

7. Best R, Lewis DA, Nasser N. The anti-ulcerogenic activity of the unripe plantain banana (Musa species). Br J Pharmacol. 1984 May;82(1):107-16. PMID: 6329384.

8. Goel RK, Sairam K. Anti-ulcer drugs from indigenous sources with emphasis on Musa sapientum, Tamrahbasma, Asparagus racemosus and Zingiber officinale. Indian J Pharmacol. 2002;34:100-10.

9. Gupta N, Gupta SK, Shukla VK, Singh SP. An Indian communitybased epidemiological study of wounds. J Wound Care. 2004 Sep;13(8):323-5. PMID: 15469216.

10. Liu J, Ren H, Xu J, Bai R, Yan Q, Huang W, Wu X, Fu J, Wang $\mathrm{Q}, \mathrm{Wu} \mathrm{Q}, \mathrm{Fu} \mathrm{R}$. Total synthesis and antihypertensive activity of (+/-)7,8-dihydroxy-3-methyl-isochromanone-4. Bioorg Med Chem Lett. 2009 Mar 15;19(6):1822-4. doi: 10.1016/j. bmcl.2008.12.102. 
11. Ashcroft GS, Mills SJ, Ashworth JJ. Ageing and wound healing. Biogerontology. 2002;3(6):337-45. PMID: 12510172.

12. Simões MJ, Cabral ACV, Boyaciyan K, Kulay Jr L, Sasso WS. Ultrastructural aspects of fibroblasts and macrophages during the healing process of the skin of rats. Rev Paul Med. 1986 MayJun;104(3):132-5.

13. Modolin M, Bevilacqua RG. Wound healing: synthesis of the recent acquisitions. Rev Bras Clin Ter. 1985 Jun;14(6):208-13.

14. Selema MD, Farago ME. Trace element concentrations in the fruit peels and trunks of Musa paradisiaca. Phytochemistry. 1996 Aug;42(6):1523-5. PMID: 8783837.

15. Singer AJ, Clark RA. Cutaneous wound healing. N Engl J Med. 1999 Sep 2;341(10):738-46. PMID: 10471461.

\section{Correspondence:}

Dênia Amélia Novato Castelli Von Atzingen

Faculdade de Ciências Médicas Dr. José Antônio Garcia Coutinho, UNIVÁS

Avenida Coronel Alfredo Custódio de Paula 320, Campus Central

37550-000 Pouso Alegre - MG Brasil

Tel.: (55 35)3423-6495 / 9964-8151

danovato@uai.com.br

Received: May 11, 2015

Review: July 13, 2015

Accepted: Aug 122015

Conflict of interest: none

Financial source: $\mathrm{CNPq}$

'Research performed at the "Dr. José Antônio Garcia Coutinho" School of Medical Sciences, Universidade do Vale do Sapucaí (UNIVÁS), Pouso Alegre - MG, Brazil. 